\title{
EDITORIAL
}

\section{LAS CIENCIAS SOCIALES EN LA SOCIEDAD DEL CONOCIMIENTO}

\author{
SOCIAL SCIENCES IN THE KNOWLEDGE SOCIETY
}

Horacio Díaz Rojas ${ }^{1}$

\begin{abstract}
Si entendemos la ciencia como la búsqueda de conocimiento en cualquier área del saber, observaremos que ha existido desde los inicios de la humanidad, con diferentes niveles de protagonismo, pero siempre con el objetivo de potenciar el desarrollo y elevar la calidad de vida de la sociedad.

La historia así lo demuestra. Hace miles de años la rueda y el cultivo fueron claros ejemplos de lo que hoy llamaríamos ciencia aplicada; su contribución al trabajo de la tierra, que en aquellos tiempos era el insumo principal, fue lo que marcó la denominada sociedad agrícola. Sin embargo, la escasa capacidad científica se manifestó en un lento progreso de la sociedad, por lo que tuvieron que pasar miles de años para que el avance de la sociedad tuviera un claro y marcado punto de inflexión, esto recién ocurre hace 300 años con la invención de la máquina a vapor y el surgimiento así de un nuevo factor de desarrollo: el capital. Nacía así la sociedad industrial, marcada por el auge del comercio y el inicio de grandes transformaciones sociales.

En esta época el desarrollo de la investigación científica es más intenso, es el tiempo de las grandes teorías y leyes; en particular en el estudio de los fenómenos naturales, como por ejemplo la materia, la tierra, la luz, etc., conceptos que hoy se engloban en las denominadas ciencias naturales. Sin lugar a dudas este auge de la investigación contribuye al desarrollo de múltiples beneficios para la sociedad, en particular, y solo por citar uno de ellos, el surgimiento de la electricidad y sus diversas aplicaciones, hito que marca el mundo actual y que pareciera que siempre ha sido parte de la humanidad; sin embargo, el empleo de la electricidad como fuente energética del desarrollo, desde una perspectiva histórica, es muy reciente, solo 100 años.
\end{abstract}

De esta forma en la sociedad industrial, el trabajo y el capital se transforman en factores básicos para el desarrollo productivo y social, donde el crecimiento económico pareciera dar respuesta a los requerimientos de la sociedad.

El incremento y apoyo a las ciencias, junto a los importantes cambios sociales hacen que rápidamente de la sociedad industrial se pase a la sociedad de la información, transitando desde la vida analógica a la vida digital y pasando del intercambio de objetos al intercambio de información, un hito en este ámbito son las redes de comunicación y en particular Internet, que como la conocemos hoy no tiene más de 20 años. Junto a ello una vorágine de aplicaciones que una vez más contribuyen a potenciar el desarrollo y elevar la calidad de vida de la sociedad.

Así llegamos a la época actual donde aparecen conceptos como sustentabilidad, igualdad de oportunidades, equidad, entre otros principios, que demuestran que el desarrollo social es tan o más relevante aun que el desarrollo productivo.

En este contexto, surge la pregunta ¿cómo seguir creciendo en un mundo donde los datos, la tecnología y la información han pasado a ser temas cotidianos?

Con un claro sesgo económico, para muchos la respuesta está en lo que los economistas denominan la productividad total de los factores (PTF), dicho de forma sencilla, ya no es suficiente con disponer solo de mano de obra (trabajo) y capital, sino que hay que optimizar diversos elementos que influyen en la PTF, donde la eficiencia y productividad son algunos de los fundamentales.

La respuesta a la pregunta planteada está en el conocimiento, que se transforma así en un

Universidad de Tarapacá, Director General de Investigación. Correo electrónico: hdiaz@uta.cl 
factor de producción; sin embargo, la capacidad de generar conocimiento reside en las personas con altos niveles de formación, surgiendo así el concepto de capital humano avanzado y la urgente necesidad de construir capacidades de investigación, desarrollo e innovación (I+D+i), que son la base para la denominada economía del conocimiento.

De esta manera, la ciencia se transforma en la protagonista de la sociedad actual; recordemos que etimológicamente la palabra ciencia viene del latín scientia que significa conocimiento, por lo tanto, la sociedad del conocimiento es la sociedad de la ciencia.

Si bien en este relato se han tomado ejemplos de desarrollo fundamentalmente del ámbito de las ciencias naturales, no quiere decir que las ciencias sociales no hayan tenido hitos también relevantes. Si recordamos que las ciencias sociales son el estudio de la sociedad y del comportamiento de las personas y su influencia en el mundo que nos rodea, es posible observar que de manera natural se están fortaleciendo en la sociedad del conocimiento, entre otras razones, por lo ya comentado. En la actualidad, el desarrollo social es tanto o más relevante que el desarrollo productivo. Prueba de ello es el establecimiento de múltiples líneas de investigación de naturaleza social y el fortalecimiento de las redes de cooperación, como por ejemplo la ISSRN (red de investigadores en ciencias sociales) que agrupa en un formato open access a más de 500.000 investigadores del área.

Así las ciencias sociales, donde se distinguen disciplinas como la demografía, la economía y negocios, la educación, la antropología, las leyes, la política, la psicología, la sociología, el trabajo social, entre otras, tienen una amplia oportunidad de desarrollo en la sociedad del conocimiento y enfrentan hoy nuevos y múltiples desafíos.

Por lo tanto, además de contribuir a explicar cómo funciona nuestra sociedad ante los rápidos cambios que están ocurriendo en el mundo moderno, debe integrarse a las ciencias naturales; porque la investigación en la sociedad del conocimiento implica una concepción integradora y multifuncional con el fin de obtener mejores respuestas a un determinado problema. En tal sentido, ya existen múltiples iniciativas como la arqueología-matemática, historiageografía, salud-antropología, biología-arqueología, etc. Sin embargo, existe un amplio espectro de colaboración no explotado y que marcará algunas áreas de investigación futuras y potenciará aún más el impacto de las ciencias sociales.

Por otro lado, las ciencias sociales también deben vincularse entre sí, pero con un estricto apego al método científico. Sergio Bagú -uno de los grandes pensadores de la teoría social latinoamericana- lo grafica de esta forma: "Cuando un sociólogo busca en la perspectiva histórica un instrumento que le permita esclarecer mejor su propio panorama, o bien cuando un historiador se vuelca hacia el análisis sociológico de una coyuntura, lo que ocurre es que tanto uno como otro, en el afán por enriquecer su propia capacidad de análisis, atraviesan los lindes de su especialidad y se van ubicando en esa frontera incierta donde lo sociológico se transforma en histórico y a la inversa".

Por último, señalar que también hay un desafío de la sociedad con las ciencias sociales, en particular en lo que se refiere a la cuantificación de su productividad, marcada hoy por modelos cienciométricos que no siempre son aplicables de forma directa a los contextos de las diversas disciplinas sociales. 